\title{
Heme oxygenase 1 overexpression increases iron fluxes in Caco- 2 cells
}

\author{
MARÍA JOSÉ MENDIBURO, SEBASTIÁN FLORES, FERNANDO PIZARRO \\ and MIGUEL ARREDONDO
}

Micronutrient Laboratory, Nutrition and Food Technology Institute, Universidad de Chile, Santiago, Chile

\begin{abstract}
Heme oxygenase- 1 is a microsomal enzyme that, when induced by stress, protects the cells from oxidative injury. Heme oxygenase- 1 participates in the cleavage of the heme ring producing biliverdin, $\mathrm{CO}$ and ferrous Fe. The released Fe becomes part of intracellular Fe pool and can be stored in ferritin or released by an iron exporter. The mechanism by which heme enters cells is not completely understood, although it had been suggested that it might be internalized by an endocytosis process. In this study, we expressed a full-length Heme oxygenase- 1 cDNA in Caco- 2 cells and measured intracellular iron content, heme-iron uptake and transport and immunolocalization of heme oxygenase- 1 in these cells. We found that heme oxygenase-1 expressing cells showed increased apical heme iron uptake and transepithelial transport when compared to control cells. These results suggested that heme oxygenase- 1 mediates heme iron influx and efflux in intestinal cells.
\end{abstract}

Key terms: iron, heme, heme oxygenase, Caco-2 cells

\section{INTRODUCTION}

Heme oxygenase-1 (HO1) is a microsomal enzyme that, when induced by stress, protects the cells from oxidative injury (Poss and Tonegawa, 1997a). HO1 participates in the cleavage of the heme ring producing biliverdin, $\mathrm{CO}$ and ferrous $\mathrm{Fe}$. The released $\mathrm{Fe}$ becomes part of intracellular $\mathrm{Fe}$ pool and can be stored in ferritin or released by an iron exporter. The mechanism by which heme enters cells is not completely understood. It has been suggested that it might be internalized by an endocytosis process (Worthington et al., 2001). In mice lacking a functional HO1, it was shown that this enzyme is necessary for cellular iron efflux (Poss and Tonegewa, 1997b; Ferris et al., 1999). Since HO1 is not an iron transport protein, the mechanism by which HO1 activity modulates cellular iron efflux remains unknown. In this study, we cloned a fulllength HO1 cDNA, expressed it in Caco-2 cells, and measured intracellular iron content, iron transport and HO 1 immunolocalization in these cells.

\section{RESULTS}

HO1 sub-cellular localization changes in cells overexpressing HO1. The internal distribution of $\mathrm{HO} 1$ was determined by immunofluorescence in stable clones of Caco2 cells transfected with the pcDNA3.1 vector (control cells) or with pcDNA3.1-HO1 (HO1 cells). In control cells, the distribution of HO1 is mainly perinuclear (Fig. 1A). However, in HO1 cells, the expression of HO1 was higher and also detected at a peripheral compartment (Fig. 1B). 


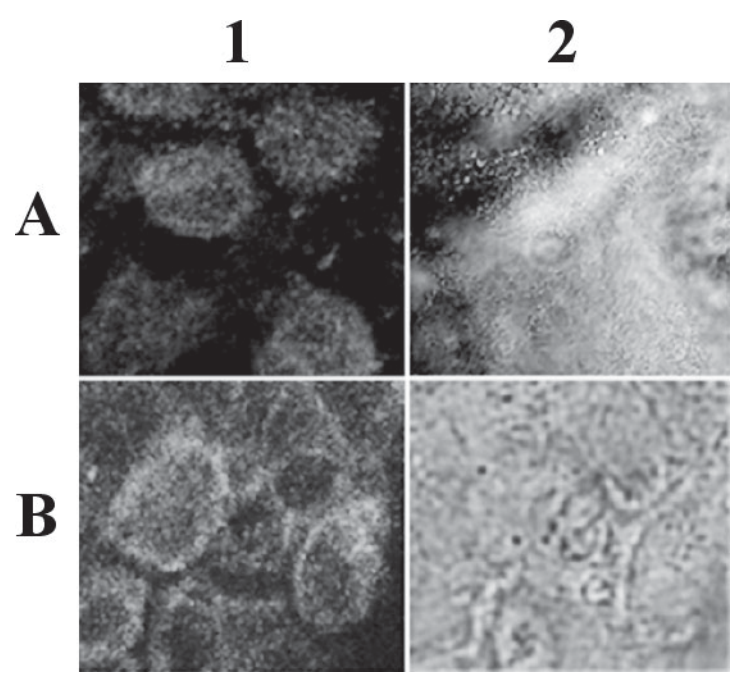

Figure 1: HO1 detection by immunofluorescence in Caco-2 cells. Control (A) or HO1-transfected cells (B) were fixed, permeabilized and incubated with anti-HO1 (1: 100, Santa Cruz Biotechnology) followed with incubation with anti-IgG-Alexa 498. Cells were then observed by confocal microscopy. 1: HO1 fluorescence; 2: phase contrast of the same fields.

HO1-transfected cells show increased iron content. Total iron content was determined in control and HOl cells incubated for 7 days with different heme concentrations (Fig. 2). Both control and HO1 cells increased their iron content with increased heme in the culture medium, but HO1 cells had higher intracellular iron content compared to control cells for any of the extracellular heme concentrations tested. This result suggests that $\mathrm{HO} 1$ increases heme-Fe uptake and that HO1 mediates heme iron influx and efflux in these cells. Since the net increase in heme iron influx was larger that the net increase in heme iron efflux (Fig. 3, compare values in $A$ and $B$ ), the result will be iron accumulation by these cells, as shown in figure 2 .

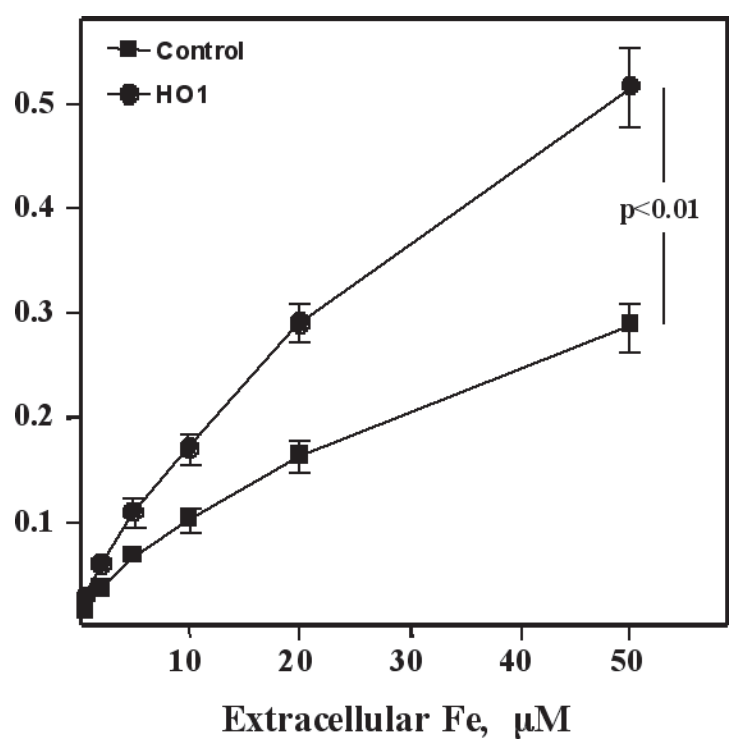

Figure 2: Intracellular Fe content. Control and HO1 cells were grown for 7 days in 12-well plates with different $(0.5$ to $50 \mu \mathrm{M})$ heme-Fe concentrations. Intracellular iron content was determined by atomic absorption spectrometry with a spectrometer equipped with graphite furnace (Simaa 6100, Perkin Elmer Instruments). Data represent mean $\pm \mathrm{SD}$ of 3 independent experiments.

\section{DISCUSSION}

HO1 intracellular localization changed from a perinuclear to a putative plasma membrane topology when cells overexpressed HO1. This change correlated with increased intracellular Fe concentration and increases in apical uptake of heme iron and increased basolateral iron efflux. These results suggest that HO1 may be regulating the heme uptake process by these cells. It also may be possible that the increased heme iron apical uptake observed is a consequence of increased basolateral hemeiron efflux. In this case, Ireg1 could be the main target of increased HO1 expression. Further experiments are necessary to elucidate the possible molecular interactions between HO1 and the apical and basolateral iron transporters. 
A

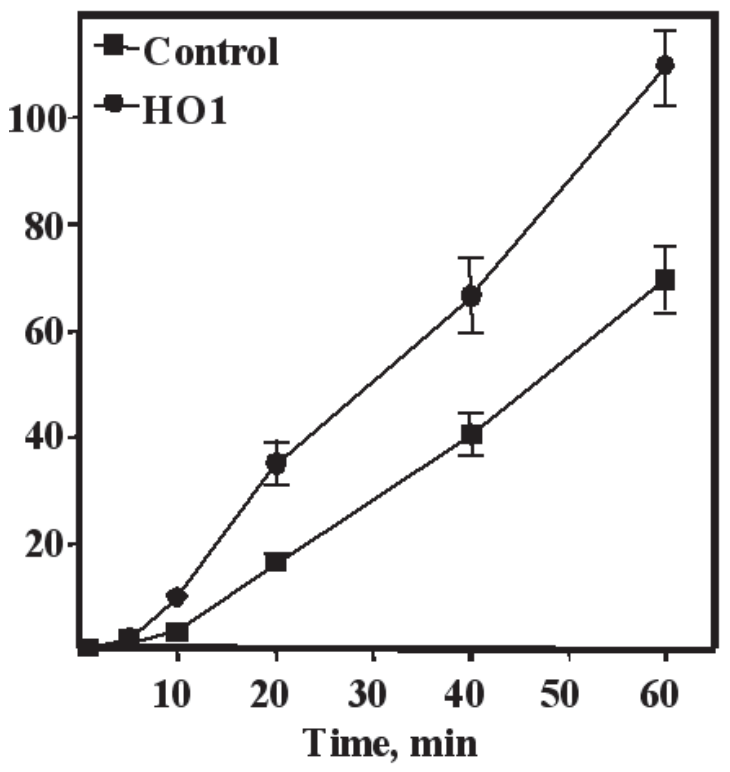

B

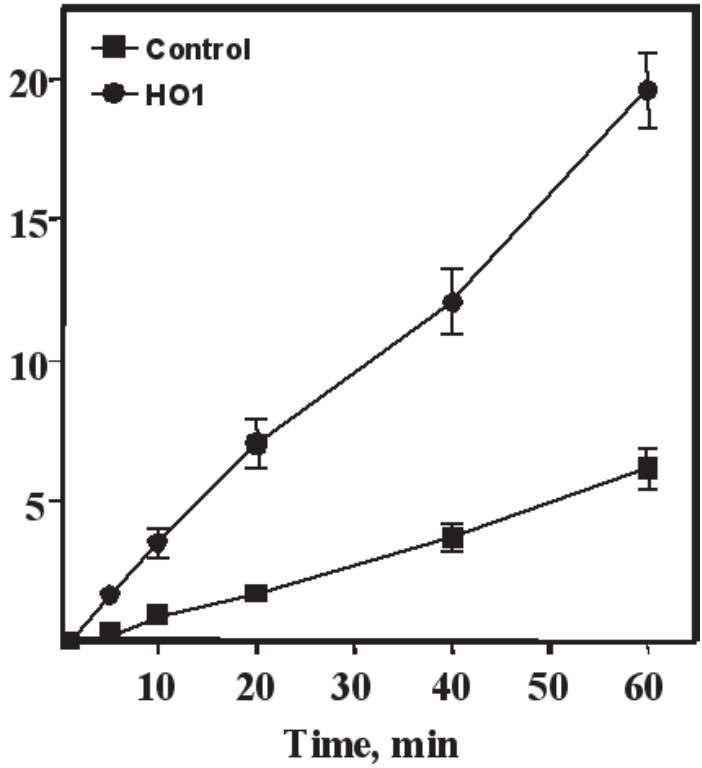

Figure 3: Heme-Fe uptake and basolateral transport assay. Control and HO1 Caco-2 cell grown for 2 weeks in a bicameral chamber system were incubated for $0,5,10,20,40$ and 60 min with 50 $\mu \mathrm{M}{ }^{55} \mathrm{Fe}$-labeled heme in the apical chamber. A: Apical ${ }^{55} \mathrm{Fe}$ uptake. B: Apical-to-basolateral ${ }^{55} \mathrm{Fe}$ transport. Values are mean \pm SD of 3 independent experiments.

\section{ACKNOWLEDGEMENTS}

This work was financed by FONDECYT grant 1030633 .

\section{REFERENCES}

FERRIS C, JAFFREY S, SAWA A, TAKAHASHI M, BRADY, BARROW R, TYSOE S, WOLOSKER H, BARAÑANO D, DORÉ S, POSS K, SYNDER S
(1999) Heme oxygenase-1 prevents cell death by regulating cellular iron. Nature Cell Biology 1: 152157

POSS K, TONEGAWA S (1997a) Reduced stress defense in heme oxygenase 1-deficient cells. Proc Nat Acad Sci USA 94: 10925-10930

POSS K, TONEGAWA S (1997b) Heme oxygenase 1 is required for mammalian iron reutilization. Proc. Natl. Acad. Sci. USA 94: 10919-10924

WORTHINGTON M, COHN S, MILLER S, QI LUO R, BERG C (2001) Characterization of a human plasma membrane transporter in intestinal and hepatocyte cell lines. Am J Physiol Gastrointest Liver Physiol 280: G1172-G1177 